8 This manuscript is a preprint and will be shortly submitted for publication to a scientific 9 journal. As a function of the peer-reviewing process that this manuscript will undergo, 10 its structure and content may change.

11

If accepted, the final version of this manuscript will be available via the 'Peerreviewed Publication DOI' link on the right-hand side of this webpage. Please feel 14 free to contact any of the authors; we welcome feedback.

15

16 


\title{
Multi-temporal relative landslide risk analysis for sustainable development of rapidly growing cities
}

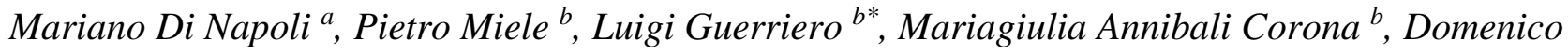 \\ Calcaterra $^{b}$, Massimo Ramondini ${ }^{c}$, Chester Sellers ${ }^{d}$, Diego Di Martire ${ }^{b}$ \\ ${ }^{\text {a }}$ Department of Earth, Environmental and Life Sciences, University of Genoa, Genoa, 16132, Italy \\ ${ }^{\mathrm{b}}$ Department of Earth, Environment and Resources Sciences, Federico II University of Naples, Naples, 80126, Italy \\ ${ }^{\mathrm{c}}$ Department of Civil, Architectural and Environmental Engineering, Federico II University of Naples, Naples, 80125, \\ Italy \\ ${ }^{\mathrm{d}}$ Instituto Ecuatoriano de Regimen Seccional (IERSE), University of Azuay, EC-01.01.981, Cuenca 010107, Ecuador \\ * Corresponding author: luigi.guerriero2@unina.it
}

\begin{abstract}
In the last decades, developing countries have experienced an increase in impact of natural disasters due to both the ongoing climate change and the sustained expansion of urban areas. Intrinsic vulnerability of settlements due to poverty and poor governance, as well as the lack of tools for urban occupation planning and mitigation protocols, have made such impact particularly severe. Cuenca (Ecuador) is a significant example of a city that in the last decades has experienced considerable population growth and an associated increasing of loss due to landslide occurrence. Despite such effects, updated urban planning tools are absent, a condition that suggested an evaluation of multitemporal relative landslide risk, here presented based on updated data depicting the spatial distribution of landslides and their predisposing factors, as well as population change between 2010 and 2020. In addition, a multi-temporal analysis accounting for risk change between 2010 and 2020 has been carried out. Due to the absence of spatially distributed data about the population, electricity supply contract data have been used as a proxy of the population. Results indicate that current higher relative risk is estimated for municipalities (parroquias) located at the southern sector of the study area (i.e. Turi, Valle, Santa Ana, Tarqui and Paccha). Moreover, the multi-temporal analysis indicates that most municipalities of the city located in the hilly areas that bound the center (i.e. Sayausi, San
\end{abstract}


Joaquin, Tarqui, Valle, Sidcay, Banos, Sidcay, Ricaurte, Paccha and Chiquintad), experiencing sustained population growth, will be exposed to an increased risk with a consistently growing trend. This information is consistent with landslide susceptibility data derived by a machine learning-based analysis that indicate higher susceptibility to landslides in hilly areas surrounding the city center. The obtained relative risk maps can be considered as a useful tool for guiding land-planning, occupation restriction and early warning strategy adoption. The used methodological approach, accounting for landslide susceptibility and population variation through proxy data analysis, has the potential to be applied in a similar context of growing-population cities of low to mid-income countries, where data, usually needed for a comprehensive landslide risk analysis, are only partly available.

Keywords: Landslide susceptibility; Machine learning algorithm; Relative risk assessment; Cuenca; Ecuador; Latin America.

\section{Introduction}

In the last decades, the ongoing climate change, associated with global population growth and the related expansion of urbanized areas, has been responsible for an increase in frequency and impact of natural disasters due to floods, landslides and wildfires (Knox 1993; Xu et al. 2013; Altan et al. 2015; Arnell and Gosling 2016; Gariano and Guzzetti 2016; Di Napoli et al. 2020a). Developing countries have experienced an even much severe impact, because people are often concentrated in high-hazard urban areas where housing is highly vulnerable due to poor building, and early warning systems are commonly absent (Zorn 2018; Aguirre-Ayerbe et al. 2020). The dimension of such impact can be easily understood considering that between 1996 and 2015 approximately $90 \%$ of disaster-related deaths occurred in mid to low-income countries (http://reliefweb.int/report/world/poverty-death-disaster-and-mortality-1996-2015).

Vulnerability factors such as poverty, poor governance, and the lack of experience in facing natural disaster are responsible for this effect disproportion (i.e., deaths concentration in developing 
countries; Petley, 2012). The lack of tools for urban occupation planning, prescriptions definition, and mitigation protocols, is a further element of vulnerability that particularly applies to rapidly growing urban areas prone to floods and landslides. For this reason, an evaluation and prevention of exposure to geohazards, in terms of susceptibility and hazard, is a fundamental step for the correct environment planning and management, as shown by several scientific contributions in this field (Goetz et al. 2015; Guerriero et al. 2018, 2020a, b; Lombardo et al. 2020; Segoni et al. 2020; Di Napoli et al. 2021; Novellino et al. 2021; Allocca et al. 2021).

In Latin-American countries, between 2004 and 2013, 611 landslides triggered by rainfall and earthquakes have been responsible for approximately 12000 deaths (Sepúlveda and Petley 2015). A relevant example is an event that, in 2017, involved the city of Mocoa in southern Colombia, which killed more than 300 people and destroyed 130 houses (García-Delgado et al. 2019). While the spatial distribution of such events is consistently related to a combination of slope morphometry, rainfall distribution and population density, poverty is a controlling factor of the impact to people particularly relevant in urban areas. Indeed, the presence of informal settlements and their localization has a big impact on the number of fatalities. In such conditions, landslide susceptibility and risk maps represent useful tools to develop land-planning strategies for preventing such kinds of impact and supporting the sustainable development of cities (Musakwa and van Niekerk 2015; AlQahtany and Abubakar 2020).

Landslide susceptibility indicates the probability of a slope failure occurring in an area depending on its geomorphological peculiarities (van Westen et al. 2003; Guzzetti et al. 2006; Reichenbach et al. 2018). It differs from hazard, since does not directly consider any evaluation of the expected magnitude of an event and its recurrence time (Fell et al. 2008). A landslide susceptibility map spatially reproduces the landslide occurrence likelihood providing an overview of areas that need prescriptions in settlement development perspective (Chen et al. 2020; Di Napoli et al. 2020b; Zhang et al. 2020; Arabameri et al. 2021). Landslide risk depends on the characteristics of elements at risk, their vulnerability and the temporal-spatial probability of occurrence of a damaging landslide event. 
Risk maps are powerful tools since they consider also the characteristics of exposed elements providing potential damage scenarios (Bignami et al. 2018; Novellino et al. 2021). In general terms, landslide risk is evaluated through a multi-step analysis including $i$ ) hazard identification, $i$ ) hazard assessment, iii) inventory of elements at risk and exposure, $i v$ ) vulnerability assessment and $v$ ) risk estimation (Dai et al. 2002; Glade et al. 2006; van Westen et al. 2008; Corominas et al. 2014). Due to the frequent lack of landslide occurrence timing data, risk is often evaluated by adopting a simplified approach based upon susceptibility scenarios rather than hazard (Ercanoglu 2008; Fell et al. 2008; Arabameri et al. 2017). An alternative hazard can be estimated on the basis of the return period of landslide triggering events (Grelle et al. 2014). A further element of simplification generally relates to vulnerability estimation that, especially for heterogenous settlements, could be very challenging to be correctly estimated and might cause diffuse under-or over-estimation of landslide risk (Glade 2003; Li et al. 2010; Mavrouli et al. 2014). The concept of relative risk well applies to regions where a reduced complexity estimation has to be preferred due to limits in data availability, such as in rapidly growing urban areas of developing countries (Andrejev et al. 2017).

The city of Cuenca (Ecuador) is an example of a rapidly growing city that in the last decades has experienced a sustained increase in population, having reached 400000 units. Magnitude of the change can be estimated considering that thirty years ago the total population was around 200000 units. Due to this growth, the urban area has consistently expanded from its original position within the Tomebamba River floodplain occupying surrounding hilly slopes. Such slopes are prone to landslides, so that damage to settlements and infrastructures are very frequent preventing a sustainable and safe development of the city (Miele et al. 2021). On this basis, an analysis of the relative risk to landslide and its multi-temporal variation as a function of population growth in the city of Cuenca was completed with the aim of providing $i$ ) an updated overview of relative risk exposure to landslides of population and $\mathrm{ii}$ ) a general tool for supporting land planning in rapidly growing cities suffering the effect of natural hazards such due to the lack of planning instruments. Indeed, for the city of Cuenca, a first attempt of natural hazards assessment dates back to the early 
1990s with a pilot project called PRECUPA (PREvention ECuador CUenca PAute). In the perspective of the analysis, an integrated method consisting of $i$ ) landslide inventory construction through both remote-sensing data analysis and field observations, ii) machine-learning-based susceptibility assessment by using Maximum Entropy algorithm, iii) electricity supply contract analysis for exposure quantification and $i v$ ) relative risk estimation, was used.

\section{Study area}

The study area comprises the city of Cuenca and the surrounding hilly area being increasingly occupied by settlements (Fig. 1). Cuenca is the capital of the Azuay province of Ecuador and extends over an area of approximately $124 \mathrm{~km}^{2}$. In 1999, the historic center of the city has been inserted in the UNESCO World Heritage Site list due to its importance as a cultural and governmental center of the Canari and Inca civilizations, and for being an example of renaissance urban planning in the Americas during the Spanish colonial period.

The city lies within an inter-Andean valley, which was formed following a compressional deformation controlled by major NE-trending faults (Noblet et al. 1988; Hungerbühler et al. 2002). The geology of this area is represented by Mesozoic marine and subaerial sedimentary deposits, covering the Paleozoic metamorphic basement (Noblet et al. 1988). The sedimentary series is more than 2400 and $3500 \mathrm{~m}$ thick and is formed by two main sequences separated by a regional unconformity. The lower sequence consists of fluvial and brackish delta plain deposits containing ubiquitous metamorphic pebbles from the Cordillera Real. From the bottom, this series is made up of the Biblián, Loyola, Azogues and Mangan Formations that include sandy clays, laminated shales with gypsum, tuffaceous sandstones, siltstones and conglomeratic sandstones. The upper sedimentary sequence is composed of volcanic clast-bearing rocks of the Turi Formation, which is divided into Turi and Santa Rosa members, and consists of tuffaceous coarse sandstones, volcanic clast-supported conglomerates, matrix-supported volcanic breccias and minor tuff layers. Furthermore, the late Miocene volcanic series of Tarqui Formation crops out in the area unconformably covering a wide 
range of volcanic and Tertiary sedimentary formations. The Tarqui formation is formed by two members: $i$ ) the Tarqui Member formed by poorly consolidated and intensely weathered red volcanic airfall deposits and ii) the Llacao Member represented by debris-flow deposits of volcanoclastic materials (Steinmann 1997).

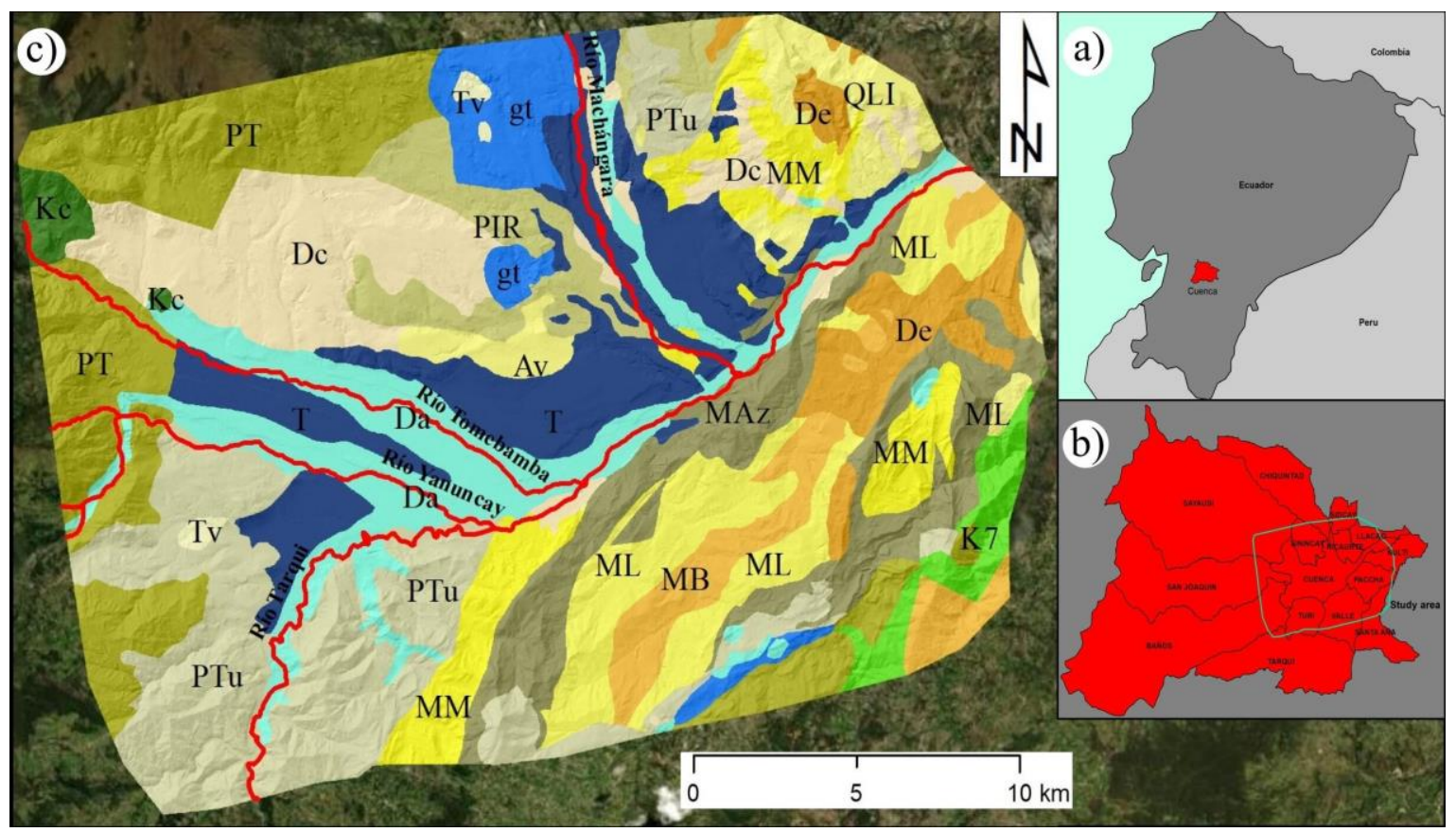

Fig. 1. a) Geographic location of the study area; b) Cuenca municipalities, the green box shows the location of the considered area for the analysis; c) Cuenca geological map (refer to Table 1 for geology types' code description). Red lines represent the four principal rivers that cross Cuenca town.

This area is known for frequent landslides involving settlements and infrastructures (Fig. 2). For instance, the buildings of the Faculty of Philosophy of the University of Azuay is consistently affected by slow-moving landslides and periodically damaged by slope deformation (Sellers et al., 2020). On March 29, 1993, a large landslide (20 million $\mathrm{m}^{3}$ ) took place northeast of Cuenca city, damming the Paute river and causing the formation of an artificial lake that flooded fertile land and destroying houses, roads, railways and a regional thermoelectric plant (Plaza et al. 2011). In addition, the segment of the Pan-American Highway crossing the city is continuously affected by landslides inducing damage and, in some cases, vehicle accidents (Miele et al. 2021). The high frequency of landslides is related to the significant yearly rainfall amount (around $900 \mathrm{~mm}$ ), the extremely high frequency of earthquakes of significant magnitude (ranging from 4.0 to $4.9 \mathrm{Mw}$ according to 

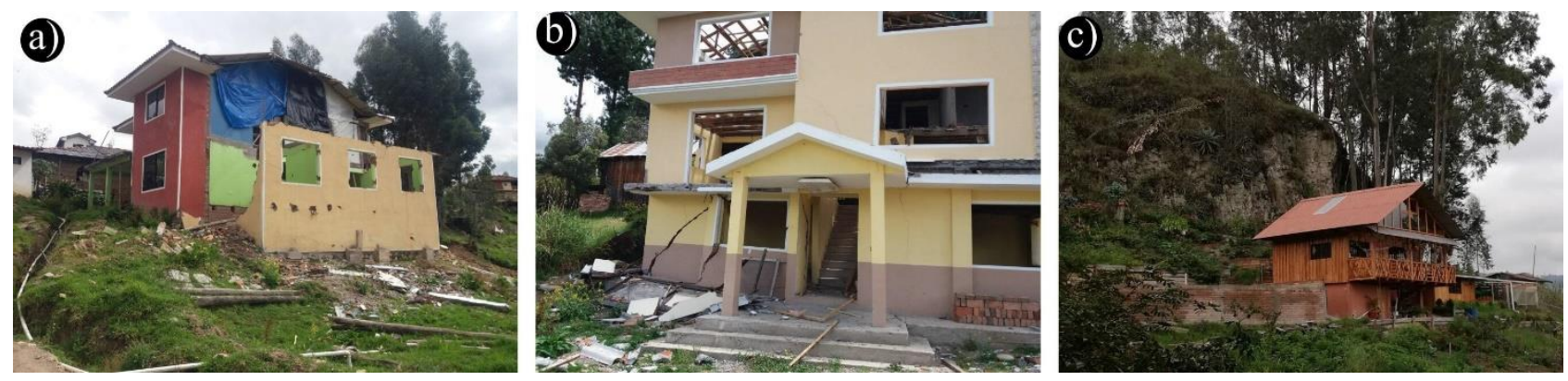

Fig. 2. a) House completely destroyed by a mass movement; b) house partially damaged due to a landslide; c) an example of low-risk perception by the local population. The structure was built close to a sub-vertical rock wall which is very prone to mass movements such as rockfalls, topples and slides (photo: M. Ramondini).

174

\section{Data and methods}

To evaluate the relative risk to landslides of the population of the city of Cuenca and its multitemporal variation in relation to population growth, a method consisting of landslide mapping, machine-learning-based susceptibility analysis, population growth estimation through energy supply contract analysis and relative risk evaluation was executed (Fig. 3). Below, details of data and methods used for the estimation are provided.

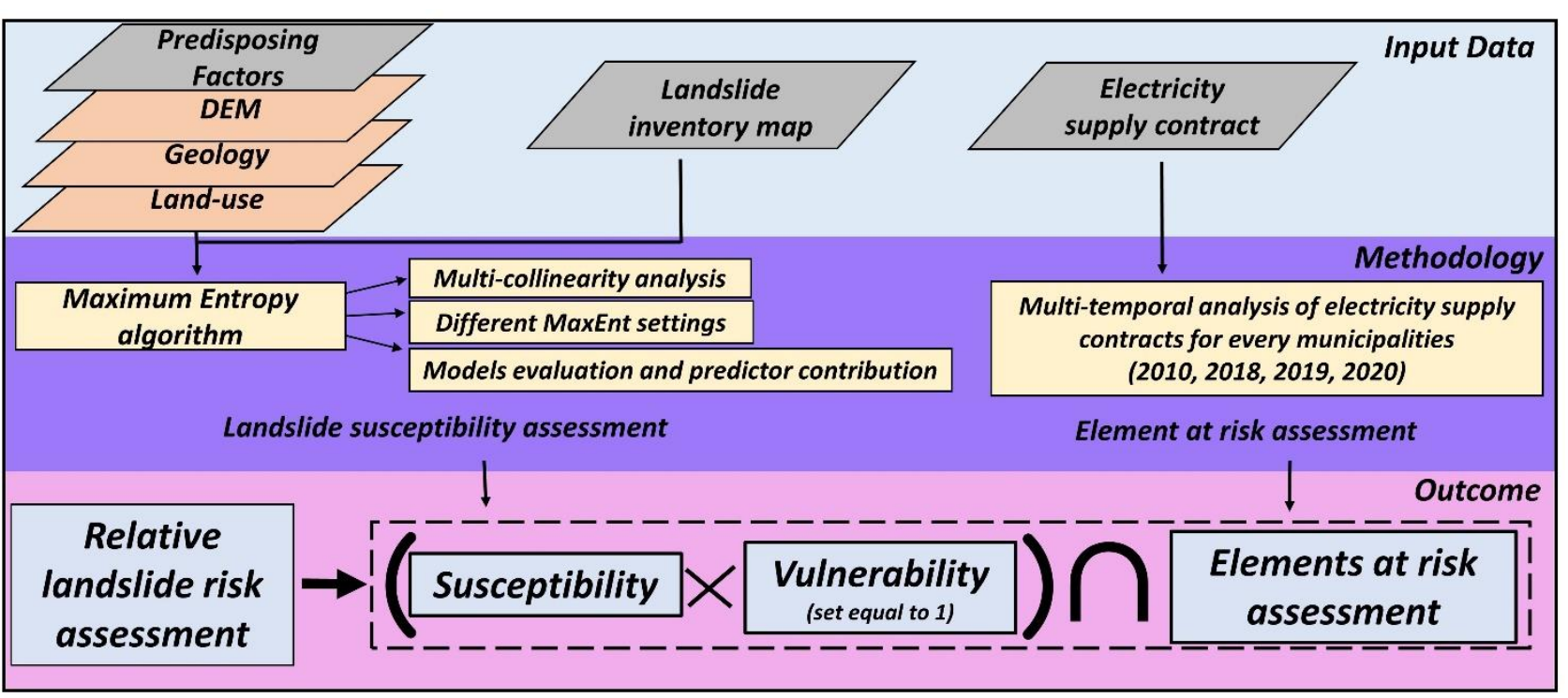




\subsection{Landslide inventory map}

In the perspective of evaluating landslide relative risk to people, the assessment of susceptibility to landslides was carried out using the available landslide inventory prepared by Miele et al. (2021) for the area surrounding the Pan-American Highway integrated by further analyses to extend the inventory to the study area. Following the method used by Miele et al. (2021), a landslide inventory was derived by interferometric data, visual interpretation of aerial imagery and field surveys. Sentinel-1A and B images (ascending and descending pass) acquired between October 2016 and May 2019 were processed using the Coherent Pixel Technique - Temporal Phase Coherence (CPT-TPC) approach (Mora et al. 2003; Iglesias et al. 2015). The obtained Line of Sight mean displacement rates were post-processed through the application of the kernel density estimation (KDE) algorithm, allowing to identify unstable areas (UAs) affected by ongoing deformations (Di Martire et al. 2016; Guerriero et al. 2019; Ammirati et al. 2020). Identified unstable areas were used as a guide for aerial imagery interpretation and subsequent field surveys. The latter were carried out between September 2020 and March 2021 using 1:5000 topographical maps as a basemap. Landslide areas derived by image analysis and field surveys were digitized into a GIS environment and classified according to Cruden and Varnes (1996).

\subsection{Electricity supply contracts analysis}

The relative landslide risk evaluation has been completed considering the population as the element at risk. To account for population growth, a multi-temporal risk assessment has been executed considering data representative of the population distribution over the study area in 2010, 2018, 2019 and 2020 (the only available years). Although population data and their future projection are available in absolute terms for the city of Cuenca, the spatial distribution over the municipalities forming the city of Cuenca is not available. Such datum is notoriously essential in any landslide risk evaluation. For this work, distribution of energy supply contracts data, derived from the IRSE (Instituto de Estudios de Régimen Seccional del Ecuador - Institute of Studies on the Sectional Regime of Ecuador, 
http://ierse.uazuay.edu.ec/), were used. Although it does not correspond to the number of people

211 living in each sector of the city, the provision of utilities (i.e., electricity supply contracts) is a proxy

212 of the population and can be considered as alternative data in relative risk assessment perspective.

213 Since energy supply contracts data consists of vector points, for each municipality such information

214 were aggregated and associated to the specific area and used for relative risk evaluation. Figures $4 \mathrm{a}$,

215 b, c and d depict the distribution of such data at the municipalities scale between 2010 and 2020 and

216 their variation in comparison with the year 2010 (Fig. 4 e, f, g).
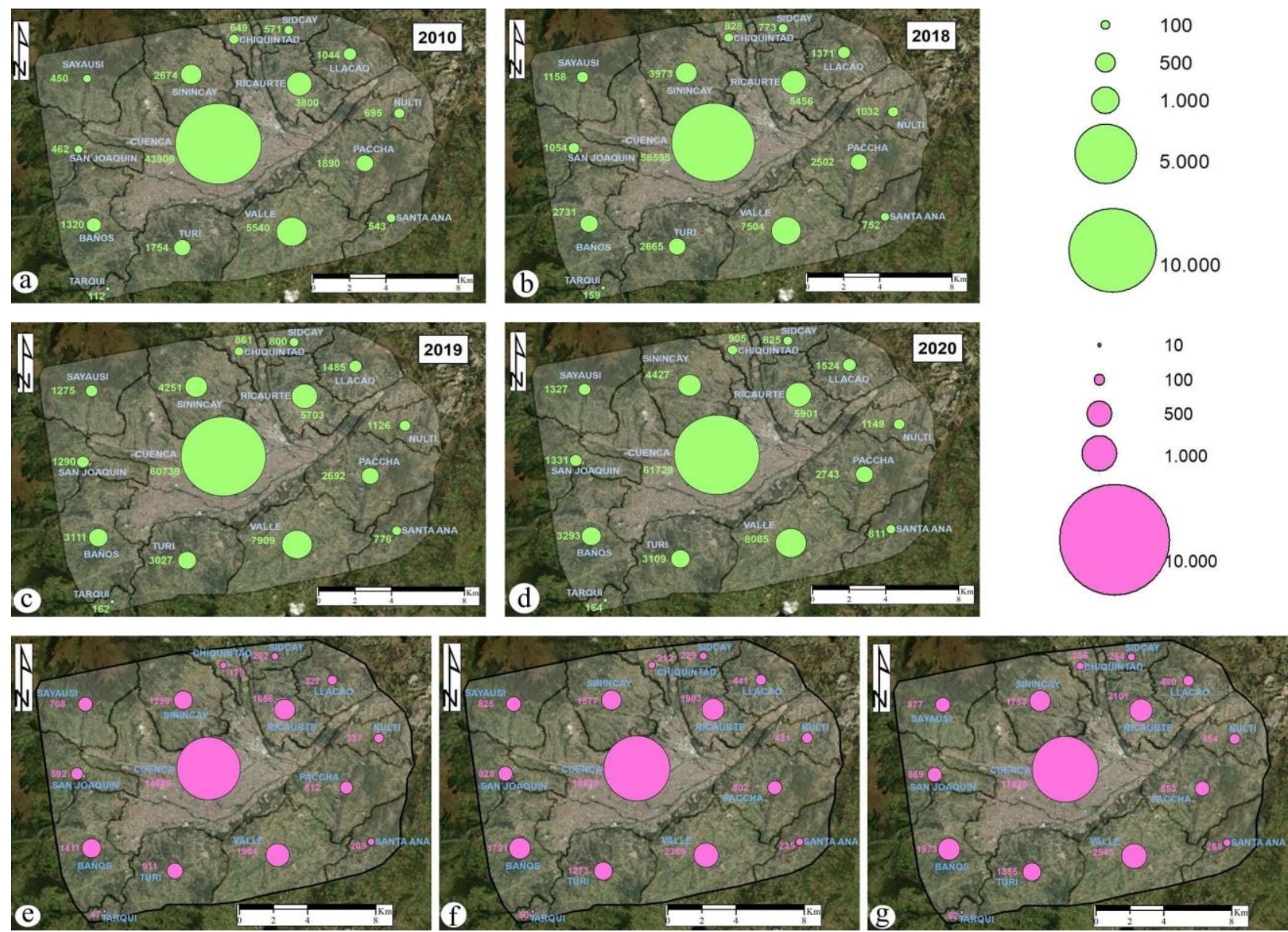

Fig. 4. a), b), c) and d) Multi-temporal municipalities evolution by analysing electricity supply contracts from 2010 to 2020; e), f) and g) Variation of power supply contracts, respectively in years 2018, 2019 and 2020, compared to 2010.

\subsection{Susceptibility analysis}

222 Based on the mapped distribution of landslides and as a first modeling step in the evaluation of the relative landslide risk in the city of Cuenca, landslide susceptibility was estimated using a machine 
learning algorithm (Lombardo et al. 2016; Di Napoli et al. 2020b, 2021). In this perspective, environmental covariates acting as potential predisposing factors for landslide initiation were selected and tested for multicollinearity. Subsequently, covariates that do not exhibit multicollinearity were used for susceptibility estimation through the MaxEnt algorithm (Phillips et al. 2006; Phillips and Dudík 2008). Results were validated using multiple criteria. Details about evaluation steps are provided below.

\subsubsection{Covariates selection and multicollinearity analysis}

For the analysis eleven covariates such as $i$ ) Slope Steepness; ii) Eastness; iii) Northness; iv) Planar and v) Profile Curvatures; vi) Topographic Wetness Index (TWI); vii) Relative Slope Position (RSP); viii) Distance to streams; $i x$ ) Distance to roads; $x$ ) Land Use; and $x i$ ) Geology were selected (Supplementary Material 1). Numerical covariates were derived from a $10 \times 10$ m Digital Elevation Model resampled from an original $3 \times 3 \mathrm{~m}$ Digital Terrain Model. DTM resampling and topographyrelated covariates raster generation were completed into a GIS environment (i.e., SAGA GIS, Conrad et al., 2015). Categorical covariates such as Land use and Geology were derived considering data available from the National Institute of Geology and Energy (https://sni.gob.ec).

In general, the likelihood of a landslide occurrence is positively correlated with slope due to its effect in modulating acting force and slope aspect. The aspect is radial in nature, with values 360 and 1 being adjacent degree measurements. A common way to treat radial data is to transform them by using trigonometric functions. A trigonometric transformation of aspect data is rather "pure" since it retains the continuity of aspect. For these data, a cos transformation measures southerliness-tonortherliness (-1 to 1 , respectively), while a $\sin$ transformation measures westerliness-to-easterliness (-1 to 1, respectively), obtaining northness and eastness (Lombardo et al. 2020). Planform curvature relates to the convergence and divergence of flow across a surface, so that it is a proxy of potential runoff concentration. Profile curvature affects acceleration and deceleration of runoff across the surface indicating the predisposition of a slope to soil erosion. Topographic Wetness Index is an 
important factor indicating the potential of runoff generation and is a proxy for the thickness of the saturation zone. Shallow landslides are facilitated by soil saturation. High index values indicate the great potential of water accumulated due to low slope angles. Relative slope position indicates the location of each cell relative to the ridge and valley of a hillslope. Distance to streams and distance to roads have been both estimated by using the Euclidean distance method. Distance to stream is a crucial parameter that controls slope stability. In fact, slope foot erosion due to stream water flow is a common triggering factor for landslide initiation. Similarly, landslide initiation can be facilitated by the presence of roads due to runoff concentration and preferential infiltration and the presence of weak material due to excavation. Land use provides information about the potential practice that might favour landslide development. Geology of a slope is a significant predisposing factor for landslide initiation since properties of slope materials effectively control initiation potential. For categorical covariates, raster cells codes were assigned according to Table 1.

\begin{tabular}{|c|c|c|c|c|c|c|c|}
\hline Variable & Code & Class & Variable & Code & Class & Code & Class \\
\hline \multirow{9}{*}{ 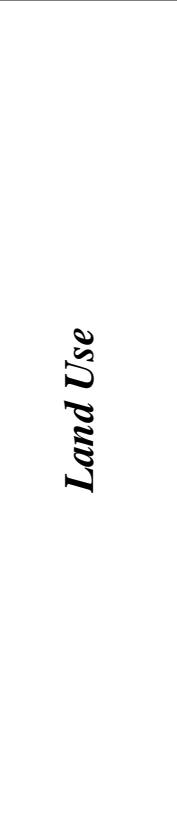 } & 1 & Bare area & \multirow{9}{*}{\begin{tabular}{l}
$\overrightarrow{0}$ \\
$\stackrel{8}{0}$ \\
\multirow{8}{0}{}
\end{tabular}} & 1 & $\begin{array}{l}\text { PT - Tarqui } \\
\text { Fm. }\end{array}$ & 10 & Kc - Celica Fm. \\
\hline & 2 & Forest & & 2 & $\begin{array}{l}\text { gt - Alluvial } \\
\text { deposit }\end{array}$ & 11 & $\begin{array}{c}\text { MAz - Azogues } \\
\text { Fm. }\end{array}$ \\
\hline & 3 & Crop & & 3 & $\begin{array}{l}\text { PIR - Santa } \\
\text { Rosa Fm. }\end{array}$ & 12 & $\mathrm{Tv}$ - Travertine \\
\hline & 4 & Moor & & 4 & $\begin{array}{l}\text { PTu - Turi } \\
\text { Fm. }\end{array}$ & 13 & $\mathrm{~T}-$ Fluvial terracce \\
\hline & 5 & Urban area & & 5 & $\begin{array}{c}\text { MM - } \\
\text { Mangan Fm. }\end{array}$ & 14 & QLI - Llacao Fm. \\
\hline & 6 & $\begin{array}{c}\text { Shrub } \\
\text { vegetation }\end{array}$ & & 6 & $\begin{array}{c}\text { MB - } \\
\text { Biblian Fm. }\end{array}$ & 15 & $\begin{array}{c}\text { Dc - Colluvial } \\
\text { deposit }\end{array}$ \\
\hline & 7 & Water course & & 7 & $\begin{array}{c}\mathrm{Da}- \\
\text { Alluvial } \\
\text { deposit }\end{array}$ & 16 & K7 - Yunguilla Fm. \\
\hline & 8 & $\begin{array}{c}\text { Corn } \\
\text { cultivation }\end{array}$ & & 8 & $\begin{array}{c}\text { ML - } \\
\text { Loyola Fm. }\end{array}$ & 17 & Av - Varvada clays \\
\hline & 9 & $\begin{array}{l}\text { Natural } \\
\text { grassland }\end{array}$ & & 9 & $\begin{array}{c}\text { De - } \\
\text { Colluvial } \\
\text { deposit }\end{array}$ & & \\
\hline
\end{tabular}

Table 1. Land use and geology types' code description.

265 Once selected, covariates were tested for multicollinearity. Multicollinearity represents the occurrence of high intercorrelations among two or more independent variables within a predictive 
model and can lead to skewed or misleading results. To identify multicollinearity among selected variables the Variance Inflation Factor (VIF) through the "usdm" package (Naimi et al. 2014) was employed. VIF measures how much of the variation in one variable is explained by the other variable. It estimates how much the variance of a coefficient is "inflated", for this reason VIF, because of linear dependence with other predictors. VIF can be calculated by using the formula $1 /\left(1-R^{2}\right)$, where $R^{2}$ is the coefficient of determination of the regression equation. The smallest possible value of VIF is one (absence of multicollinearity). As a rule of thumb, a VIF value that exceeds 5 or 10 indicates a problematic amount of collinearity (Gareth et al. 2013). However, VIF values greater than 2.50 should be treated with caution since they correspond to an $\mathrm{R}^{2}$ of 0.60 with the other variables. When faced with multicollinearity, the concerned variables should be removed, since the presence of multicollinearity implies that the information provided about the response by this variable is redundant when other variables are present (Gareth et al. 2013).

\subsubsection{Susceptibility assessment}

Landslide susceptibility was assessed using the MaxEnt modelling algorithm and identified covariates (Elith et al. 2011). MaxEnt is a presence-only (PO) spatial distribution method that deals only with landslide presence locations (Zhao et al. 2020). It makes use of occurrence data and a large (typically 10000) number of points throughout the study area, which are referred to as background points. Background points define the frequency distribution of available environmental variables in the landscape. To reconstruct the potential distribution of an event, MaxEnt calculates two probability densities. For all presence points, probability density describes the relative likelihood of all environmental variables in the model over the range of those points, describing the environment where an event has occurred. Then, the algorithm calculates the density of landslide occurrences across the entire landscape, based on the background points that characterize the available environment within the study region. Population size is typically unknown, so only relative comparisons among these rates are meaningful, resulting in a Relative Occurrence Rate (ROR; 
Fithian and Hastie, 2013). ROR can be seen as the ratio between the probability density of covariates across locations within the considered geographic space where the landslide is present and the probability density of covariates across the entire geographic space, thus obtaining insights on the relative proneness to failure of a given cell compared to another one: the map of probability of event occurrence ranges from 0 (i.e., no landslide probability) to 1 (highest landslide probability).

Since MaxEnt predictions are sensitive to initial modelling settings (Merow et al. 2013), different MaxEnt implementations were evaluated through the ENMeval R package (R Core Team 2021) to detect the settings that optimize the trade-off between goodness-of-fit and overfitting (Muscarella et al. 2014). In fact, MaxEnt is possible to set up two main parameters: 1) feature classes and 2) regularization multiplier. Feature class represents a mathematical transformation of the different covariates used in the model to allow complex relationships to be modelled (Elith et al. 2010). The regularization multiplier is a parameter that adds new constraints, in other words, is a penalty imposed on the model. The main goal is to prevent over-complexity and/or overfitting by controlling the intensity of the chosen feature classes used to build the model (Elith et al. 2010). For a detailed explanation of feature classes and regularization multipliers, it is recommended to consult Merow et al., (2013). For the analysis, regularization values between 0.5 and 10 , with 0.5 steps were investigated, and the following feature classes were considered: linear, linear + quadratic, hinge, linear + quadratic + hinge, linear + quadratic + hinge + product, and linear + quadratic + hinge + product + threshold (Muscarella et al. 2014).

\subsubsection{Model evaluation and predictor contribution}

Model evaluation was completed using spatial block cross-validation scheme (Muscarella et al. 2014) implemented in ENMeval. This method converts part of occurrence records and background points into evaluation bins and uses them to reduce spatial - autocorrelation between training and validation points that can overinflate model performance in presence of biased sampling (Hijmans 2012; Wenger and Olden 2012). The block cross-validation scheme proved able to assess model transferability, i.e., 
the ability to extrapolate predictions into new areas (Roberts et al. 2017) and to penalize models based on meaningless predictors (Fourcade et al. 2018).

Because no consensus currently exists regarding the most appropriate metric or approach to evaluate the performance of models (Fielding and Bell 1997; Warren and Seifert 2011; Peterson et al. 2011), different statistical approaches have been adopted to assess the models' predictive performance with presence-background data (Muscarella et al. 2014). In this case, the best model reliabilitycombination has been chosen following three criteria: $i$ ) lowest delta Akaike Information Criteria ( $\triangle \mathrm{AICc}$ ) (Burnham and Anderson 2002), ii) Area Under the Curve plot based on the training data $\left(\right.$ AUC $\left._{\text {train }}\right)$ (Hanley and McNeil 1982) and iii) the difference between training and testing AUC (AUC diff (Warren and Seifert 2011).

$\mathrm{AIC}_{\mathrm{c}}$ is calculated using the full data set and its metrics are not affected by the method chosen for data partitioning. AIC is a single number score that can be used to determine which of multiple models is most likely to be the best model for a given dataset. It estimates models likelihood in a relative manner, meaning that AIC scores are only useful in comparison with other AIC scores for the same dataset. A lower AIC score indicates higher model performance. AIC is most frequently used in situations where one is not able to easily test the model's performance on a test set. Furthermore, AIC results are reported as $\Delta \mathrm{AIC}_{\mathrm{c}}$ scores because it is the easiest way to calculate and interpret them. The $\Delta \mathrm{AIC}_{\mathrm{c}}$ is the relative difference between the best model and each other model in the dataset. The formula is the following (Eq. 1):

$$
\triangle \mathrm{AICc}=A I C_{i}-\min A I C
$$

where:

$A I C_{i}$ is the score for the particular model $i$, and $\min A I C$ is the score for the "best" model.

Hence, AIC values closely to zero o equal to zero indicate the best model with the available dataset. The AUC is the measure of the ability of a classifier to distinguish between classes and is used as a summary of the Receiver Operator Characteristic (ROC) curve, which is an evaluation metric for binary classification problems. A high AUC, which ranges between 0 and 1, indicates that sites with 
high predicted suitability values tend to be areas of known presence, while locations with lower model prediction values tend to be areas where the landslide is not known to be present (absent or random point). Lastly, to quantify overfitting, ENMeval calculates the difference between training and testing AUC (AUC diff $)$, which is expected to be high with overfit models.

Moreover, the Landslide Ratio of each predicted landslide susceptibility class ( $\left.\mathrm{LR}_{\text {class}}\right)$ has been employed as a further performance evaluation of the landslide model. $\mathrm{LR}_{\text {class }}$ is based on the ratio of the number of unstable sites contained in each susceptibility class, in relation to the total number of actual landslide sites, according to the predicted percentage of area in each class of susceptibility category (Eq. 2). This index was developed specifically to deal with situations when boundaries of observed landslides are not available, but where their locations are known. The advantage of using $\mathrm{LR}_{\text {class }}$ index is that it considers both the predicted stable and unstable areas and thus significantly decreases over-prediction.

$$
L R_{\text {class }}=\frac{\% \text { of contained sites in each susceptibility class }}{\% \text { of predicted landslide areas in each susceptibility class }}
$$

$\mathrm{LR}_{\text {class }}$ index indicates that if a slope failure occurs, the predicted unstable area has a chance equal to $\mathrm{LR}_{\text {class }}$ of including an actual slope failure. A larger value of $\mathrm{LR}_{\text {class }}$ corresponds to a lower overprediction by the model (Park et al. 2013).

Predictive performance estimation is only a partial metric of model goodness. Predictor contributions represent a further key step that should be assessed to comprehensively estimate the validity of a model for relating results to the analyzed processes. In this contribution, the investigation has been carried out considering 1) predictor importance and 2) percentage contribution (Oke and Thompson 2015). Predictor importance represents the degree to which single environmental variables are contributing to the final model, so that the percent contributions for all predictors in a model sum to $100 \%$ (Phillips 2008). The percentage contribution, called permutation importance, is determined by randomly altering the values of that variable among the training points (both presence and background) and measuring the resulting decrease in training AUC. A large decrease indicates that 
the model depends heavily on that variable (Phillips 2017). A very useful and detailed explanation was given by Bradie and Leung (2017).

\subsection{Relative risk analysis}

Considering the definition of risk introduced by Varnes (1984) as "the expected number of lives lost, persons injured, damage to property and disruption of economic activity due to a particular damaging phenomenon for a given area and reference period", landslide risk can be assessed qualitatively (Wang et al. 2013) or quantitatively (Chang et al. 2021). Generally, for a wide area, where the quality and quantity of available data are inadequate for quantitative analysis, a qualitative risk evaluation may be more appropriate (Andrejev et al. 2017). In the context of the proposed analysis, data from susceptibility analysis and electricity supply contracts were used as a basis for multi-temporal landslide risk evaluation over the study area. The evaluation was completed considering only the risk for people. As for landslide susceptibility, results of the estimation derived by the described Machine Learning-based approach were employed. As for people at risk quantification, the number of power supply contracts and their relative variation between 2010 and 2020 (i.e. 2010, 2018, 2019 and 2020) were considered in the assumption that the number of contracts is a good proxy of people distribution over the study area. The use of this proxy well fits the choice of evaluating the risk due to landslide in a relative manner. Indeed, relative risk is considered as the intersection of the landslide susceptibility and the number of elements exposed to landslides (Andrejev et al. 2017). In the case of the city of Cuenca, the number of elements at risk (i.e. people) is not fully known in terms of spatial distribution and the presence of electricity supply contracts location, indicating the number of groups of people for each location, represents somehow an opportunity to overcome this issue. Since both landslide susceptibility and power supply contract are georeferenced, but supply contracts are not regularly distributed, the relative risk assessment was completed at the scale of the municipalities of the city. Obtained outcomes in the form of relative risk histograms, depicting the number of electricity supply contracts located in each susceptibility class, were classified using the Sturges method 
(Sturges 1926), which allows highlighting how over time the different areas of the city of Cuenca underwent an increase in contracts and therefore also in relative risk.

\section{Results and discussion}

\subsection{Landslide inventory map}

The obtained LIM is composed of 710 landslides detected through different approaches and all validated thanks to field surveys. Landslide database contains useful information regarding the type of movement according to Cruden and Varnes (1996), state of activity, location, triggering factor (i.e., precipitation or anthropic), geology, land use, velocity and further information. In the database, it is possible to recognize rockfalls $(72-10.1 \%)$, topples $(3-0.4 \%)$, flows $(8-1.1 \%)$, spreads $(5-0.7 \%)$, rotational slides $(550-77.1 \%)$ and translational slides $(72-10.1 \%)$ (Fig. 5a). These phenomena represent the principal hazard of the area, since they affect the urban area damaging roads networks and buildings. The main causes of landslides triggering are intense or prolonged rainfalls and mining activity (i.e. incorrect management of the excavation face; Jaboyedoff et al., 2016).

Geostructural aspects notably influence the occurrence of gravitational phenomena involving rock masses such as falls, topples and planar slides. Rockfalls and topples affect steep artificial slopes around the main infrastructures (Miele et al. 2021). In fact, these phenomena mainly occur where anthropic actions have provoked cutting linked to the construction of infrastructures. The high slope angles represent an essential element in favouring translational slides (Raso et al. 2020), whose action is often enhanced by diffuse and channelled erosion operated by running water.

\subsection{Multicollinearity examination}

Table 2 shows the results of multicollinearity analysis carried out through VIF estimation and its comparison with a predefined threshold value. In this regard, it must be noted that there is no unequivocal and approved threshold in the scientific literature. However, it is generally accepted that 
VIF values higher than 10 indicate severe collinearity (Hair et al. 2010), even though this rule of thumb lacks a theoretical basis (Gómez et al. 2016).

423 The employment of many environmental covariates might lead to overfitting problems, but, in this work, the individual predisposing factor values differ considerably from the aforementioned 425 threshold. Based on Table 2, the highest VIF value is 2.02, corresponding to the Topographic Wetness 426 Index, while the smallest ones are 1.01 and 1.02, which are associated with Northness and Eastness, respectively. Accordingly, there are no environmental variables that exceed the critical value, and thus, these results satisfy the criterion (VIF $<5$ ) proving that there is no multicollinearity among the landslide PFs.

Table 2. Multicollinearity analysis for the landslide environmental factors.

\begin{tabular}{c|c}
$\begin{array}{c}\text { Environmental } \\
\text { Variables }\end{array}$ & $\begin{array}{c}\text { Variance Inflation } \\
\text { Factor }\end{array}$ \\
\hline Slope steepness & 1.72 \\
Eastness & 1.02 \\
Northness & 1.01 \\
Planar curvature & 1.39 \\
Profile curvature & 1.30 \\
Topographic Wetness & 2.02 \\
Index & 1.39 \\
Relative Slope Position & 1.12 \\
Distance to stream & 1.19 \\
Distance to road &
\end{tabular}

\subsection{Landslide susceptibility}

Figure $5 \mathrm{~b}$ shows the result of landslide susceptibility analysis in the form of a susceptibility map subdivided into five classes through Natural Breaks distribution (Jenks 1967). Each class represents a specific susceptibility range including very low, low, moderate, high and very high susceptibility levels. Natural Breaks classification, also called Jenks optimization method, is a data classification method designed to determine the best arrangement of values into different classes. This is done by seeking to reduce the standard deviation value within each class and maximizing that between the 
439 classes themselves (Basofi et al. 2018; Novellino et al. 2021). The percentage of susceptibility classes 440 is summarized in Table 3.

441 As reported in the map, the most susceptible areas of the city of Cuenca are observable at 442 mountainsides that border the city. In these areas, slopes are steep and concave, and roads create local 443 discontinuities. The central part of the map is characterized by very low and low susceptibility zones, 444 and represent the Cuenca urban area, located in the plain which is characterized by the presence of 445 alluvial deposits and different terraces orders. Along the Tomebamba shores, due to the erosive action 446 of the rivers affecting the foot of the slopes, there are areas predisposed to landsliding with a medium 447 to very high susceptibility. Periurban and rural areas, instead, are in medium to very high 448 susceptibility areas where there are steeper mountainsides.
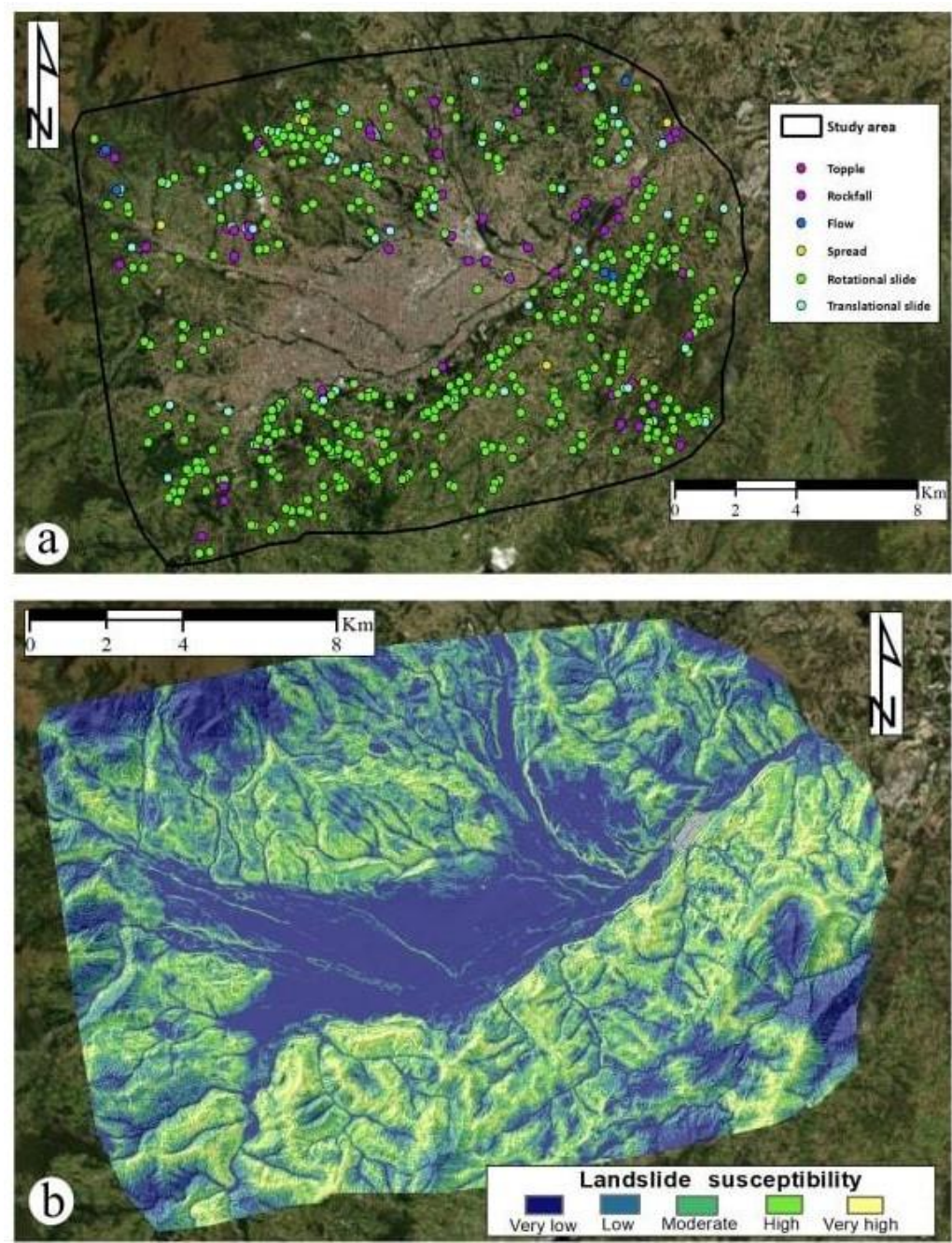

450 Fig. 5. a) Landslide inventory map of Cuenca. Landslides are represented as points (data source modified from Miele et 451 al. (2021); b) landslide susceptibility map of the study area obtained by means of MaxEnt algorithm implementation. 


\subsection{Susceptibility model validation}

453 According to Swets (1988), the obtained models have achieved fair-to-good predictive performance, with AUC values ranging from 0.763 to 0.866 (Fig. 6). The lower value is associated with models with linear or linear + quadratic features and high regularization values (i.e., 9.5 and 10). The higher value is associated with a model with all features and low regularization values (i.e., 0.5 and 1 ).

$\mathrm{AUC}_{\text {diff }}$ values scored from 0.06 to 0.14 . Among the resulting 120 combinations, the one reporting the lowest $\triangle \mathrm{AIC}_{\mathrm{c}}$ has been chosen. The selected model is characterized by the following peculiarity: linear + quadratic + hinge + product + threshold features, AUC value of 0.82 , average AUC difference value of 0.08 and $\triangle \mathrm{AIC}_{\mathrm{c}}$ value equal to 0 (for further information refer to Supplementary Material 2).
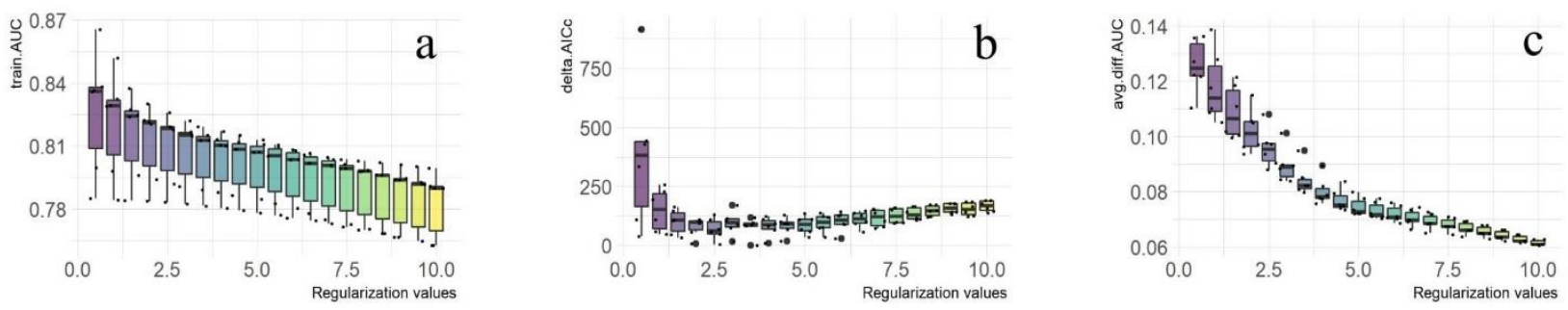

Fig. 6. a) Boxplot of AUC training data ( $\mathrm{AUC}_{\text {train }}$ - train.AUC); b) the lowest difference between the best model and each other model in the dataset $\left(\triangle \mathrm{AIC}_{\mathrm{c}}-\right.$ delta. $\left.\left.\mathrm{AIC}\right) ; \mathrm{c}\right)$ difference between training and testing $\mathrm{AUC}\left(\mathrm{AUC}_{\mathrm{diff}}-\right.$ avg.diff.AUC).

The availability of a LIM has made possible the evaluation of model performance also considering field data. Intersecting the landslide detachment points and the final susceptibility map, it has been possible to achieve information about landslide distribution and areal extent of the susceptibility classes. Areas characterized by high and very high susceptibility involve $15.5 \%$ and $10.6 \%$ of the total study area, respectively (Table 3). Very low and low susceptibility classes cover about 55\% of the study area, falling into the central sectors, namely Cuenca city. The remaining portions are assigned to the moderate (19.4\%) class. Moreover, the highest concentration of landslides can be found within the highest susceptibility class values (high, $25.2 \%$, and very high, 48.9\%). In addition, about $3 \%$ falling into the very low susceptibility class and the remaining $22.9 \%$ are distributed in the 
LR $_{\text {class }}$ percentage for each susceptibility class. As it can be noted, the highest LR $_{\text {class }}$ value corresponds to the very high susceptibility class and more than $80 \%$ falling into high and very high susceptibility values. This evidence roughly implies that, if a landslide occurs, then the predicted susceptible area has about an $80 \%$ chance of including the landslide itself.

Table 3. Summary of Maxent outcomes in landslide simulations.

\begin{tabular}{c|ccccc}
$\begin{array}{c}\text { Susceptibility } \\
\text { classes }\end{array}$ & $\begin{array}{c}\text { Landslide site } \\
(\boldsymbol{a})\end{array}$ & $\begin{array}{c}\text { \% of landslide } \\
\text { site }(\boldsymbol{c})=\boldsymbol{a} / \boldsymbol{b}\end{array}$ & $\begin{array}{c}\text { \% of predicted } \\
\text { area }(\boldsymbol{d})\end{array}$ & $\begin{array}{c}\boldsymbol{L} \boldsymbol{R}_{\text {class }} \\
(\boldsymbol{e})=\boldsymbol{c} / \boldsymbol{d}\end{array}$ & $\begin{array}{c}\text { \% of } \boldsymbol{L} \boldsymbol{R}_{\text {class }} \\
\boldsymbol{\boldsymbol { e }} \text { e/f }\end{array}$ \\
\hline Very low & 14 & 3.0 & 30.6 & 0.1 & 1.4 \\
Low & 44 & 9.4 & 23.9 & 0.9 & 5.3 \\
Moderate & 63 & 13.5 & 19.4 & 0.7 & 9.4 \\
High & 118 & 25.2 & 15.5 & 1.6 & 21.9 \\
Very high & 229 & 48.9 & 10.6 & 4.6 & 62.0 \\
\hline Sum & $468(b)$ & 100 & 100 & $7.9(f)$ & 100
\end{tabular}

The spatial aggregation of the susceptibility map confirmed that the largest part of the study region has a low susceptibility to the occurrence of landslide events. Therefore, results highlight that almost $75 \%$ of actual landslides were localized in the high and very high susceptibility classes. Also, the higher susceptibility classes showed higher values of $L_{\text {class }}$ percentages. These outcomes show significant agreement in quantitative terms between the simulated scenario and landslides inventory map. All the produced analysis permits zoning the complex territory of the Cuenca area to identify the spatial probability of landslides initiation in areas characterized by specific conditions materialized by the considered environmental variables. Moreover, landslide distribution is characterized by an increasing trend when passing from the lowest to the highest classes of susceptibility. These observations highlight that, despite the limited area extension of the very high susceptibility class, most of the landslides surveyed fall within the latter. Furthermore, the results of this elaboration have made clear the need for preventive action, perhaps based on simple monitoring techniques, to avoid the worsening of local geoenvironmental conditions. 


\subsection{Factors predisposing slope instability}

497 As the latest outcome, the variables contribution has been accomplished. This result allows 498 understanding which variables have greater importance in the final models' implementation. Table 4 499 presents the impact of each variable. In particular, the results reveal that the highest conditioning 500 variables (i.e. the variables that assume a fundamental role in the final landslide susceptibility map) 501 are slope steepness, distance to roads and planform curvature. So this means that a model with a 502 higher fit is achieved through the aforementioned variables. In general, when percent contribution 503 was observed it is desirable to see a nice spread of values. Conversely, if the contribution of a variable 504 is high in the model (i.e. higher than 70\%) something is not right and that variable is not encompassing 505 many variations or that variable is correlated with a bunch of other variables. Other variables, such 506 as distance to streams, land use, geology and relative slope position show noteworthy values in the 507 model. Lastly, low values close to zero are assigned to eastness, northness, profile curvature and 508 Topographic Wetness Index.

Table 4. Variable contribution values of environmental factors.

\begin{tabular}{|c|c|c|}
\hline $\begin{array}{c}\text { Environmental } \\
\text { Variables }\end{array}$ & $\begin{array}{c}\text { Percent } \\
\text { contribution }\end{array}$ & $\begin{array}{c}\text { Permutation } \\
\text { importance }\end{array}$ \\
\hline Slope steepness & 26.6 & 26.6 \\
\hline Eastness & 1.7 & 0.7 \\
\hline Northness & 0.1 & 0.4 \\
\hline Planar curvature & 19.5 & 15.7 \\
\hline Profile curvature & 0.8 & 0.8 \\
\hline $\begin{array}{c}\text { Topographic Wetness } \\
\text { Index }\end{array}$ & 0.2 & 0.1 \\
\hline Relative Slope Position & 6.1 & 1.5 \\
\hline Distance to stream & 6.0 & 5.5 \\
\hline Distance to road & 20.3 & 26.6 \\
\hline Geology & 9.1 & 8.2 \\
\hline Land use & 9.4 & 10.6 \\
\hline
\end{tabular}


511 Primary roles in the slope stability are related to slope steepness, which always influence the water 512 infiltration, upslope flow intensity and gravity force effect on safety factor against slope instability 513 (Huat et al. 2006). A particular condition is related to the presence of road cuts that influences water 514 infiltration and flows as well due to impervious pavement surface. An additional fundamental 515 covariate contribution on this zone's stability is represented by the planar curvature that adjusting the 516 convergence or divergence of water in the direction of landslide movement and landslide material 517 (Ohlmacher 2007). Furthermore, in the Cuenca territory, hillsides with planar curvature are the most 518 susceptible to earth and debris flows, and earth and debris slides. Indeed, this factor is used to identify 519 gullies (Wieczorek et al. 1997), and debris flow initiation areas can be recognized where the curvature 520 values are negative (Park et al. 2016). Finally, another important predisposing action to slope stability 521 is related to geology. Unconsolidated material such as alluvial, colluvial deposits or pyroclastic 522 lithologies deriving from the near volcanoes' activity cover the surrounding mountainous landscape, 523 determinating a very high susceptibility to sliding.

\subsection{Relative risk assessment}

Figure 7 provides an overview of relative risk in each municipality updated to 2020 . As observable from the inset graphs, the relative risk is higher in boroughs that surround the southern portions of Cuenca, namely Turi, Valle, Santa Ana, Tarqui and Paccha. Such boroughs show a higher number of energy supply contracts (i.e. element at risk) in high and very high landslide susceptibility classes.

On the contrary, the northern sectors of the study area report a lower number of power supply contracts included in the higher landslide susceptibility class. Lastly, the central portion of the study area, in which the city of Cuenca falls, is characterized chiefly by very low and low landslide risk values. However, recently, the city of Cuenca has experienced a substantial demographic increase which has led to the construction of buildings in notoriously very high susceptibility areas. Similar problems can be easily found in other rapidly expanding cities where the construction of new boroughs takes place in the hilly and mountainous areas that are more prone to instability (Di Martire 

into the highest susceptibility classes.
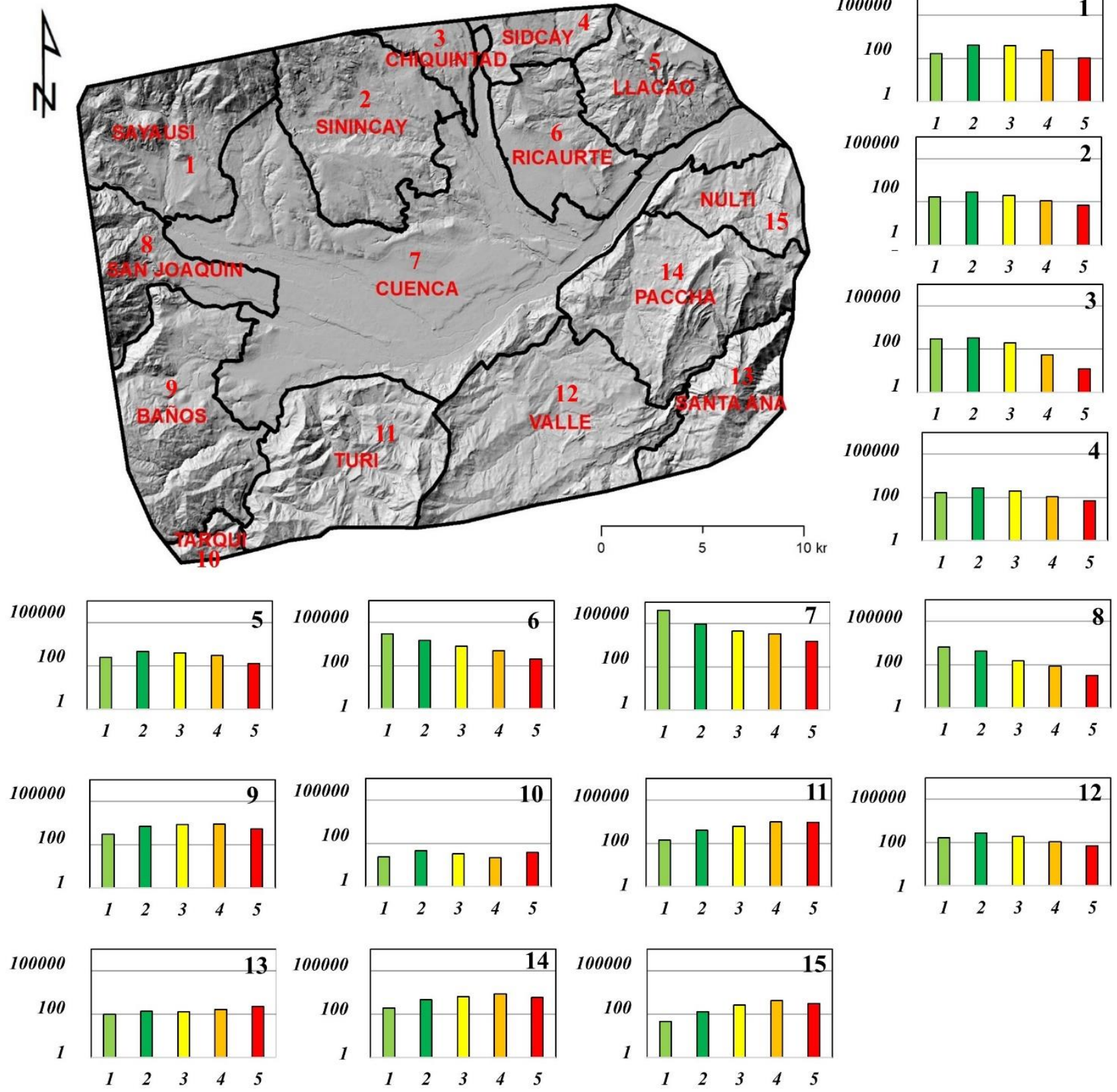

Fig. 7. Landslide risk outcome. The graphs, on a logarithmic scale, highlights the electricity supply contracts numbers for each risk class (1: very low; 2: low; 3: moderate; 4: high; 5: very high). The numbers in the upper-right corner of the graphs represent the municipalities of the studied area.

Since the city has experienced consistent growth of population between 2010 and 2020 with a sustained occupation of peri-urban hilly areas characterized by higher susceptibility to landslide in comparison to the center of the city, a specific exploration of the spatial and temporal rate of change 
of both electricity supply contracts and relative risk for each municipality is reported in Figure 8 . In particular, in Figure 8, graph "a" highlight electricity supply contracts for each landslide susceptibility class obtaining percentage of change of the relative landslide risk from 2010 to 2020, while the same rate in terms of total risk change (i.e. normalized to the total 100\%) is reported in graph "b". In addition, the relative areal extension of different susceptibility classes is also reported on graph "a" (violet bar). In the reference period, the municipality of Sayausi, San Joaquin, Tarqui, Valle, Sidcay, Banos, Ricaurte, Paccha and Chiquintad experienced a higher increase in electricity supply contacts located in very high susceptibility class corresponding to an increase in relative landslide risk (Fig. 8). Such an increase, in comparison with 2010, ranged between 33\% of Paccha and 300\% of Sayausi. Conversely, the municipalities of Turi, Nulti, Santa Ana and Cuenca experienced a higher increase in electricity supply contacts located in very low to medium susceptibility class corresponding, in most of the cases, to a decrease in relative landslide risk. Such an increase, in comparison with 2010, ranged between $20 \%$ of Cuenca and $100 \%$ of Nulti.

However, in absolute terms, the districts of Tarqui, Turi, Nulti and Santa Ana show the highest relative risk with the highest number of electricity supply contracts located in high susceptibility areas between 2018 and 2020. Conversely, the boroughs of Sayausi, Sidcay, Ricaurte, Cuenca and Ciquintad show the lowest relative risk with the lowest number of electricity supply contracts located in high susceptibility areas in the same period. In the supplementary materials (Supplementary Material 3), it is possible to consult the tables that quantitatively represent the graphs shown in Figure 8.

Landslide susceptibility is a widely used tool to assess the areas most prone to instability. In the last decade, these analyzes have also been conducted in emerging and developing countries (O'Hare and Rivas 2005; Klimeš and Rios Escobar 2010; Listo and Carvalho Vieira 2012; Jamalullail et al. 2021). Several attempts have been made to estimate landslide risk in various contexts where demographic growth is very pronounced (Rahman 2012; Listo and Carvalho Vieira 2012; Rojas et al. 2013; Alcántara-Ayala and Moreno 2016). Considering the high growth rate recorded in the last few years, 
573 it is appropriate to assess the exposure of the landslide risk over time. This type of analysis made it 574 possible to identify the most critical areas and sectors of the city of Cuenca also in terms of risk 575 evolution due to population growth. The outcome of the analysis represents a significant land 576 planning tool for the definition of urban occupation plans, land-use prescriptions, and mitigation 577 protocols that should be applied to reduce the impact of a landslide occurring in urban areas (Klimeš 578 et al. 2020; Sultana and Tan 2021). The problem of landslides involving settlements and claiming 579 human lives is of particular significance in low to mid-income countries because people are often 580 concentrated in high-hazard urban areas and vulnerability factors like poorly building of housing, 581 poor governance and the lack of experience in facing natural disasters and the absence of early 582 warning systems consistently exacerbate landslide impact (Petley 2012; Zorn 2018; Aguirre-Ayerbe 583 et al. 2020).

584 This qualitative procedure for evaluating the landslide exposure in Cuenca tries to provide 585 information for risk assessment, useful in a preliminary stage of regional planning or for more detailed 586 studies on the high-exposure areas. Therefore, the procedure proposed in this study could be 587 implemented when not all the information useful for the risk assessment are attainable. Exposure 588 quantification, which is a basic input in spatial and risk reduction planning, is the main objective of 589 this study. It is important to mention that, as not all the information are available, landslide risk values 590 are not expressed in absolute terms, but relative landslide risk could be a good proxy of districts that 591 have encountered, in the last decade, a population growing falling into very high-risk territories. 592 Notwithstanding the limitations, this study has allowed estimating which areas are more prone to 593 instability, which areas have a high relative landslide risk and also to establish the changes of risk in 594 future by consulting the trend in the different municipalities. 

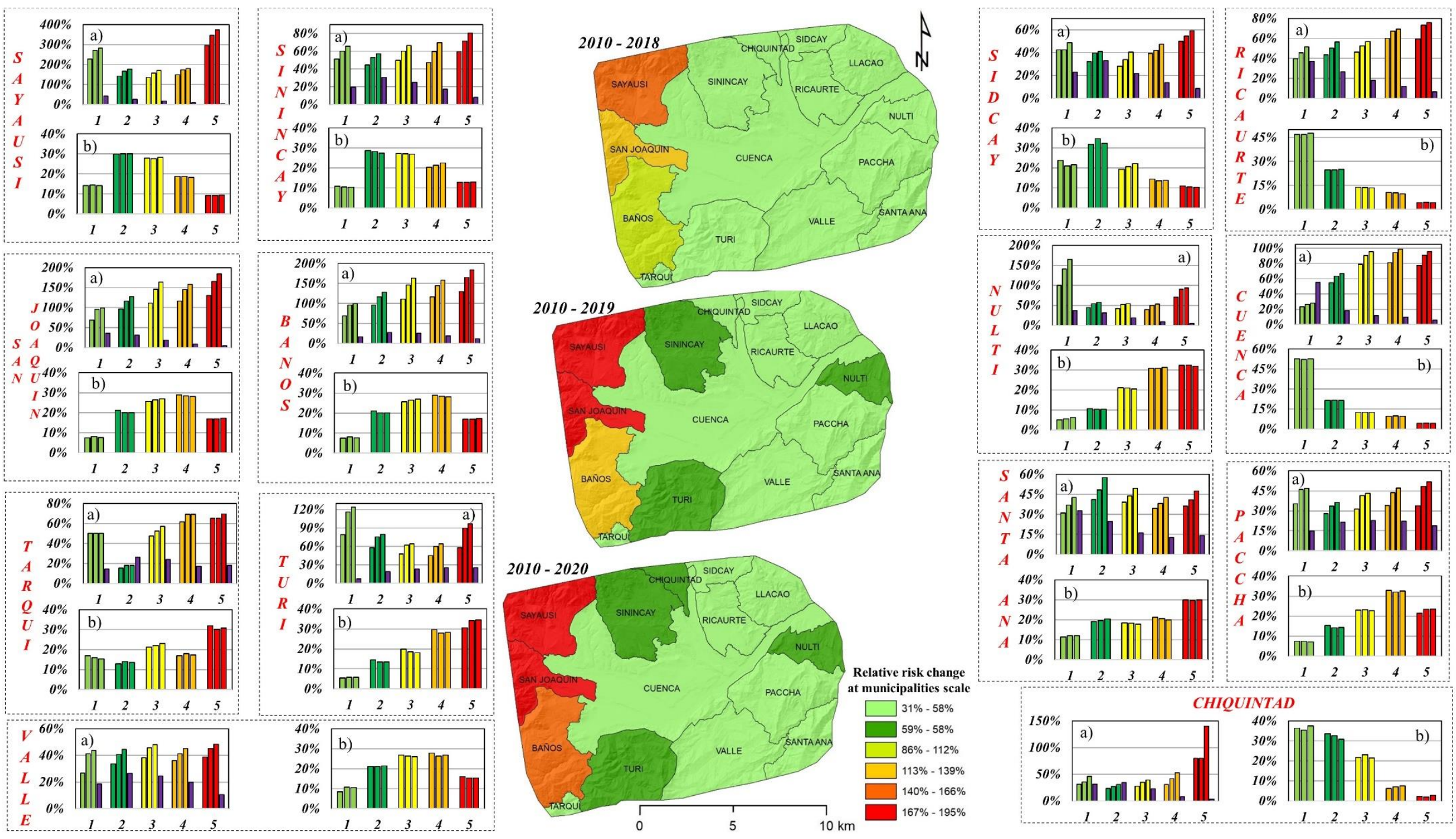

Fig. 8. Multi-temporal evolutionary perspective of relative risk to a landslide. Graphs "a" highlight electricity supply contracts for each landslide susceptibility class; graphs "b" represent the same rate in terms of total risk, namely normalized to the total $100 \%$. The coloured bars of the histograms indicate the different risk classes ranging from very low to very high, the violet bar, included in the histogram "a", specifies the landslide susceptibility classes areal extension. 


\section{Conclusions}

600 In this paper, an analysis of relative landslide risk, and its multi-temporal variation between 2010 and 601 2020, for the city of Cuenca in Ecuador (Latin America) has been presented. This study provided 602 insights into important issues such as $i$ ) the effect of the sustained expansion of urban areas due to

603 604 605 606 607 608 609 610 611 612 population growth on relative landslide risk variation and $i$ ) reduced complexity method of risk assessment in the presence of partial data only (i.e. landslide susceptibility rather than hazard, and electricity supply contracts rather than population distribution). Results indicate that current higher relative risk is estimated for districts located at the southern sector of the study area (i.e. Turi, Valle, Santa Ana, Tarqui and Paccha). In addition, the multi-temporal analysis indicates that most boroughs of the city located in the hilly areas that bound the center (i.e. Sayausi, San Joaquin, Tarqui, Valle, Sidcay, Banos, Sidcay, Ricaurte, Paccha and Chiquintad), experiencing sustained population growth, will be exposed to an increased risk with a sustained growth trend. This is also connected to the overall high vulnerability of settlements that, in many cases, is related to poorly building and the absence of early warning systems.

The obtained results can be considered a relevant tool for future land planning in the town of Cuenca, despite their resolution, limited to the municipalities area. The proposed method, using potentially available data also for mid and low-income countries (i.e. landslide inventory and a proxy of population distribution), has the potential to be applied in many contexts where a minimum dataset is available or can be developed on the basis of either field or remote sensed data. The results of the risk analysis are useful for ranking the municipalities in order of increasing risk and for supporting decision-makers in prioritising funding for risk mitigation measures.

\section{Acknowledgements}




\section{References}

Aguirre-Ayerbe I, Merino M, Aye SL, et al (2020) An evaluation of availability and adequacy of Multi-Hazard Early Warning Systems in Asian countries: A baseline study. International Journal of Disaster Risk Reduction 49:101749. https://doi.org/10.1016/j.ijdrr.2020.101749

Alcántara-Ayala I, Moreno AR (2016) Landslide risk perception and communication for disaster risk management in mountain areas of developing countries: a Mexican foretaste. J Mt Sci 13:2079-2093. https://doi.org/10.1007/s11629-015-3823-0

Allocca V, Di Napoli M, Coda S, et al (2021) A novel methodology for Groundwater Flooding Susceptibility assessment through Machine Learning techniques in a mixed-land use aquifer. Science of The Total Environment 790:148067. https://doi.org/10.1016/j.scitotenv.2021.148067

AlQahtany AM, Abubakar IR (2020) Public perception and attitudes to disaster risks in a coastal metropolis of Saudi Arabia. International Journal of Disaster Risk Reduction 44:101422. https://doi.org/10.1016/j.ijdrr.2019.101422

Altan O, Alcántara-Ayala I, Baker D, et al (2015) Disaster Risks Research and Assessment to Promote Risk Reduction and Management. Sociology \& Anthropology Department Faculty Publications

Ammirati L, Mondillo N, Rodas RA, et al (2020) Monitoring Land Surface Deformation Associated with Gold Artisanal Mining in the Zaruma City (Ecuador). Remote Sensing 12:2135. https://doi.org/10.3390/rs12132135

Andrejev K, Krušić J, Đurić U, et al (2017) Relative Landslide Risk Assessment for the City of Valjevo. In: Mikoš M, Vilímek V, Yin Y, Sassa K (eds) Advancing Culture of Living with Landslides. Springer International Publishing, Cham, pp 525-533

Arabameri A, Pal SC, Rezaie F, et al (2021) Decision tree based ensemble machine learning approaches for landslide susceptibility mapping. Geocarto International 0:1-35. https://doi.org/10.1080/10106049.2021.1892210

Arabameri A, Pourghasemi HR, Yamani M (2017) Applying different scenarios for landslide spatial modeling using computational intelligence methods. Environ Earth Sci 76:832. https://doi.org/10.1007/s12665-017-7177-5 
Arnell NW, Gosling SN (2016) The impacts of climate change on river flood risk at the global scale. Climatic Change 134:387-401. https://doi.org/10.1007/s10584-014-1084-5

Basofi A, Fariza A, Safitri EI (2018) Landslide Risk Mapping in East Java, Indonesia, Using Analytic Hierarchy Process - Natural Breaks Classification. In: 2018 International Seminar on Research of Information Technology and Intelligent Systems (ISRITI). pp 77-82

Bignami DF, Dragoni A, Menduni G (2018) Assessing and Improving Flood and Landslide Community Social Awareness and Engagement via a Web Platform: The Case of Italy. Int J Disaster Risk Sci 9:530-540. https://doi.org/10.1007/s13753-018-0199-0

Bradie J, Leung B (2017) A quantitative synthesis of the importance of variables used in MaxEnt species distribution models. Journal of Biogeography 44:1344-1361. https://doi.org/10.1111/jbi.12894

Burnham KP, Anderson DR (2002) A practical information-theoretic approach, 2nd edn. Springer, New York, 2

Chang M, Cui P, Dou X, Su F (2021) Quantitative risk assessment of landslides over the ChinaPakistan economic corridor. International Journal of Disaster Risk Reduction 63:102441. https://doi.org/10.1016/j.ijdrr.2021.102441

Chen T, Zhu L, Niu R, et al (2020) Mapping landslide susceptibility at the Three Gorges Reservoir, China, using gradient boosting decision tree, random forest and information value models. $\mathrm{J}$ Mt Sci 17:670-685. https://doi.org/10.1007/s11629-019-5839-3

Conrad O, Bechtel B, Bock M, et al (2015) System for Automated Geoscientific Analyses (SAGA) v. 2.1.4. Geoscientific Model Development 8:1991-2007. https://doi.org/10.5194/gmd-8$1991-2015$

Corominas J, van Westen C, Frattini P, et al (2014) Recommendations for the quantitative analysis of landslide risk. Bull Eng Geol Environ 73:209-263. https://doi.org/10.1007/s10064-0130538-8

Cruden DM, Varnes DJ (1996) Landslides: Investigation and Mitigation. Chapter 3 - Landslide types and processes. Transportation Research Board Special Report

Dai FC, Lee CF, Ngai YY (2002) Landslide risk assessment and management: an overview. Engineering Geology 64:65-87. https://doi.org/10.1016/S0013-7952(01)00093-X 
Di Martire D, De Rosa M, Pesce V, et al (2012) Landslide hazard and land management in highdensity urban areas of Campania region, Italy. Nat Hazards Earth Syst Sci 12:905-926. https://doi.org/10.5194/nhess-12-905-2012

Di Martire D, Tessitore S, Brancato D, et al (2016) Landslide detection integrated system (LaDIS) based on in-situ and satellite SAR interferometry measurements. CATENA 137:406-421. https://doi.org/10.1016/j.catena.2015.10.002

Di Napoli M, Carotenuto F, Cevasco A, et al (2020a) Machine learning ensemble modelling as a tool to improve landslide susceptibility mapping reliability. Landslides. https://doi.org/10.1007/s10346-020-01392-9

Di Napoli M, Di Martire D, Bausilio G, et al (2021) Rainfall-Induced Shallow Landslide Detachment, Transit and Runout Susceptibility Mapping by Integrating Machine Learning Techniques and GIS-Based Approaches. Water 13:488. https://doi.org/10.3390/w13040488

Di Napoli M, Marsiglia P, Di Martire D, et al (2020b) Landslide Susceptibility Assessment of Wildfire Burnt Areas through Earth-Observation Techniques and a Machine Learning-Based Approach. Remote Sensing 12:2505. https://doi.org/10.3390/rs12152505

Elith J, Kearney M, Phillips S (2010) The art of modelling range-shifting species. Methods in Ecology and Evolution 1:330-342. https://doi.org/10.1111/j.2041-210X.2010.00036.x

Elith J, Phillips SJ, Hastie T, et al (2011) A statistical explanation of MaxEnt for ecologists. Diversity and Distributions 17:43-57. https://doi.org/10.1111/j.1472-4642.2010.00725.x

Ercanoglu M (2008) An Overview on the Landslide Susceptibility Assessment Techniques. 4

Fell R, Corominas J, Bonnard C, et al (2008) Guidelines for landslide susceptibility, hazard and risk zoning for land-use planning. Engineering Geology 102:99-111. https://doi.org/10.1016/j.enggeo.2008.03.014

Fielding AH, Bell JF (1997) A review of methods for the assessment of prediction errors in conservation presence/absence models. Environmental Conservation 24:38-49

Fithian W, Hastie T (2013) Finite-Sample Equivalence in Statistical Models for Presence-Only Data. Ann Appl Stat 7:1917-1939. https://doi.org/10.1214/13-AOAS667 
Fourcade Y, Besnard AG, Secondi J (2018) Paintings predict the distribution of species, or the challenge of selecting environmental predictors and evaluation statistics. Global Ecology and Biogeography 27:245-256. https://doi.org/10.1111/geb.12684

García-Delgado H, Machuca S, Medina E (2019) Dynamic and geomorphic characterizations of the Mocoa debris flow (March 31, 2017, Putumayo Department, southern Colombia). Landslides 16:597-609. https://doi.org/10.1007/s10346-018-01121-3

Gareth J, Daniela W, Trevor H, Robert T (2013) An Introduction to Statistical Learning: with Applications in R. Spinger

Gariano SL, Guzzetti F (2016) Landslides in a changing climate. Earth-Science Reviews 162:227252. https://doi.org/10.1016/j.earscirev.2016.08.011

Glade T (2003) Landslide occurrence as a response to land use change: a review of evidence from New Zealand. CATENA 51:297-314. https://doi.org/10.1016/S0341-8162(02)00170-4

Glade T, Anderson MG, Crozier MJ (2006) Landslide Hazard and Risk. John Wiley \& Sons

Goetz JN, Brenning A, Petschko H, Leopold P (2015) Evaluating machine learning and statistical prediction techniques for landslide susceptibility modeling. Computers \& Geosciences 81:1-11. https://doi.org/10.1016/j.cageo.2015.04.007

Gómez RS, Pérez JG, Martín MDML, García CG (2016) Collinearity diagnostic applied in ridge estimation through the variance inflation factor. Journal of Applied Statistics 43:1831-1849. https://doi.org/10.1080/02664763.2015.1120712

Grelle G, Soriano M, Revellino P, et al (2014) Space-time prediction of rainfall-induced shallow landslides through a combined probabilistic/deterministic approach, optimized for initial water table conditions. Bull Eng Geol Environ 73:877-890. https://doi.org/10.1007/s10064013-0546-8

Guerriero L, Confuorto P, Calcaterra D, et al (2019) PS-driven inventory of town-damaging landslides in the Benevento, Avellino and Salerno Provinces, southern Italy. Journal of Maps 15:619-625. https://doi.org/10.1080/17445647.2019.1651770

Guerriero L, Focareta M, Fusco G, et al (2018) Flood hazard of major river segments, Benevento Province, Southern Italy. Journal of Maps 14:597-606. https://doi.org/10.1080/17445647.2018.1526718 
Guerriero L, Ruzza G, Guadagno FM, Revellino P (2020a) Flood hazard mapping incorporating multiple probability models. Journal of Hydrology 587:125020. https://doi.org/10.1016/j.jhydrol.2020.125020

Guerriero L, Ruzza G, Calcaterra D, et al (2020b) Modelling Prospective Flood Hazard in a Changing Climate, Benevento Province, Southern Italy. Water 12:2405. https://doi.org/10.3390/w12092405

Guzzetti F, Reichenbach P, Ardizzone F, et al (2006) Estimating the quality of landslide susceptibility models. Geomorphology 81:166-184. https://doi.org/10.1016/j.geomorph.2006.04.007

Hair JFj, Black WC, Babin BJ, Anderson RE (2010) Multivariate Data Analysis: A Global Perspective (7th ed.). New Jersey: Pearson Education Inc.

Hanley JA, McNeil BJ (1982) The meaning and use of the area under a receiver operating characteristic (ROC) curve. Radiology 143:29-36. https://doi.org/10.1148/radiology.143.1.7063747

Hijmans RJ (2012) Cross-validation of species distribution models: removing spatial sorting bias and calibration with a null model. Ecology 93:679-688. https://doi.org/10.1890/11-0826.1

Huat BBK, Ali FHJ, Low TH (2006) Water infiltration characteristics of unsaturated soil slope and its effect on suction and stability. Geotech Geol Eng 24:1293-1306. https://doi.org/10.1007/s10706-005-1881-8

Hungerbühler D, Steinmann M, Winkler W, et al (2002) Neogene stratigraphy and Andean geodynamics of southern Ecuador. Earth-Science Reviews 57:75-124. https://doi.org/10.1016/S0012-8252(01)00071-X

Iglesias R, Mallorqui JJ, Monells D, et al (2015) PSI Deformation Map Retrieval by Means of Temporal Sublook Coherence on Reduced Sets of SAR Images. Remote Sensing 7:530-563. https://doi.org/10.3390/rs70100530

Jaboyedoff M, Michoud C, Nadim F, Leroi E (2016) Human-induced landslides: towards the analysis of anthropogenic changes of the slope environment. In: Landslides and Engineered Slopes: Experience, Theory \& Practice. CRC Press, Balkema, pp 217-232 
Jamalullail SNR, Sahari S, Shah AA, Batmanathan N (2021) Preliminary analysis of landslide hazard in Brunei Darussalam, SE Asia. Environ Earth Sci 80:512. https://doi.org/10.1007/s12665-021-09815-z

Jenks GF (1967) The data model concept in statistical mapping. Israel National Center Registry International Yearbook of Cartography 7, International Cartographic Association University of Ulm, ULMGermany 1967 186-190

Klimeš J, Müllerová H, Woitsch J, et al (2020) Century-long history of rural community landslide risk reduction. International Journal of Disaster Risk Reduction 51:101756. https://doi.org/10.1016/j.ijdrr.2020.101756

Klimeš J, Rios Escobar V (2010) A landslide susceptibility assessment in urban areas based on existing data: an example from the Iguaná Valley, Medellín City, Colombia. Natural Hazards and Earth System Sciences 10:2067-2079. https://doi.org/10.5194/nhess-10-20672010

Knox JC (1993) Large increases in flood magnitude in response to modest changes in climate. Nature 361:430-432. https://doi.org/10.1038/361430a0

Li Z, Nadim F, Huang H, et al (2010) Quantitative vulnerability estimation for scenario-based landslide hazards. Landslides 7:125-134. https://doi.org/10.1007/s10346-009-0190-3

Listo F de LR, Carvalho Vieira B (2012) Mapping of risk and susceptibility of shallow-landslide in the city of São Paulo, Brazil. Geomorphology 169-170:30-44. https://doi.org/10.1016/j.geomorph.2012.01.010

Lombardo L, Fubelli G, Amato G, Bonasera M (2016) Presence-only approach to assess landslide triggering-thickness susceptibility: a test for the Mili catchment (north-eastern Sicily, Italy). Nat Hazards 84:565-588. https://doi.org/10.1007/s11069-016-2443-5

Lombardo L, Opitz T, Ardizzone F, et al (2020) Space-time landslide predictive modelling. EarthScience Reviews 209:103318. https://doi.org/10.1016/j.earscirev.2020.103318

Mavrouli O, Fotopoulou S, Pitilakis K, et al (2014) Vulnerability assessment for reinforced concrete buildings exposed to landslides. Bull Eng Geol Environ. https://doi.org/10.1007/s10064014-0573-0 
Merow C, Smith MJ, Silander JA (2013) A practical guide to MaxEnt for modeling species' distributions: what it does, and why inputs and settings matter. Ecography 36:1058-1069. https://doi.org/10.1111/j.1600-0587.2013.07872.x

Miele P, Di Napoli M, Guerriero L, et al (2021) Landslide Awareness System (LAwS) to Increase the Resilience and Safety of Transport Infrastructure: The Case Study of Pan-American Highway (Cuenca-Ecuador). Remote Sensing 13:1564. https://doi.org/10.3390/rs13081564

Mora O, Mallorqui JJ, Broquetas A (2003) Linear and nonlinear terrain deformation maps from a reduced set of interferometric SAR images. IEEE Transactions on Geoscience and Remote Sensing 41:2243-2253. https://doi.org/10.1109/TGRS.2003.814657

Musakwa W, van Niekerk A (2015) Earth Observation for Sustainable Urban Planning in Developing Countries: Needs, Trends, and Future Directions. Journal of Planning Literature 30:149-160. https://doi.org/10.1177/0885412214557817

Muscarella R, Galante PJ, Soley-Guardia M, et al (2014) ENMeval: An R package for conducting spatially independent evaluations and estimating optimal model complexity for Maxent ecological niche models. Methods in Ecology and Evolution 5:1198-1205. https://doi.org/10.1111/2041-210X.12261

Naimi B, Hamm NAS, Groen TA, et al (2014) Where is positional uncertainty a problem for species distribution modelling? Ecography 37:191-203. https://doi.org/10.1111/j.16000587.2013.00205.x

Noblet C, Lavenu A, Schneider F (1988) Etude géodynamique d'un bassin intramontagneux tertiaire sur décrochements dans les Andes du Sud de l'Equateur : l'exemple du bassin de Cuenca. Géodynamique 3 (1-2):117-138

Novellino A, Cesarano M, Cappelletti P, et al (2021) Slow-moving landslide risk assessment combining Machine Learning and InSAR techniques. CATENA 203:105317. https://doi.org/10.1016/j.catena.2021.105317

O’Hare G, Rivas S (2005) The Landslide Hazard and Human Vulnerability in La Paz City, Bolivia. The Geographical Journal 171:239-258 
Ohlmacher GC (2007) Plan curvature and landslide probability in regions dominated by earth flows and earth slides. Engineering Geology 91:117-134. https://doi.org/10.1016/j.enggeo.2007.01.005

Oke OA, Thompson KA (2015) Distribution models for mountain plant species: The value of elevation. Ecological Modelling 301:72-77. https://doi.org/10.1016/j.ecolmodel.2015.01.019

Park DW, Lee SR, Vasu NN, et al (2016) Coupled model for simulation of landslides and debris flows at local scale. Nat Hazards 81:1653-1682. https://doi.org/10.1007/s11069-016-2150-2

Park DW, Nikhil NV, Lee SR (2013) Landslide and debris flow susceptibility zonation using TRIGRS for the 2011 Seoul landslide event. Natural Hazards and Earth System Sciences 13:2833-2849. https://doi.org/10.5194/nhess-13-2833-2013

Peterson AT, Soberón J, Pearson RG, et al (2011) Ecological Niches and Geographic Distributions (MPB-49). Princeton University Press

Petley D (2012) Global patterns of loss of life from landslides. Geology 40:927-930. https://doi.org/10.1130/G33217.1

Phillips SJ (2017) A Brief Tutorial on Maxent.

Phillips SJ, Anderson RP, Schapire RE (2006) Maximum entropy modeling of species geographic distributions. Ecological Modelling 190:231-259. https://doi.org/10.1016/j.ecolmodel.2005.03.026

Phillips SJ, Dudík M (2008) Modeling of species distributions with Maxent: new extensions and a comprehensive evaluation. Ecography 31:161-175. https://doi.org/10.1111/j.09067590.2008.5203.x

Plaza G, Zevallos O, Cadier É (2011) La Josefina Landslide Dam and Its Catastrophic Breaching in the Andean Region of Ecuador. In: Evans SG, Hermanns RL, Strom A, Scarascia-Mugnozza G (eds) Natural and Artificial Rockslide Dams. Springer, Berlin, Heidelberg, pp 389-406

R Core Team (2021) R: A Language and Environment for Statistical Computing

Rahman T (2012) Landslide risk reduction of the informal foothill settlements of Chittagong city through strategic design measure 
850

851

852

853

854

855

856

857

858

859

860

861

862

863

864

865

866

867

868

869

870

871

872

873

874

875

876

877

878

Raso E, Mandarino A, Pepe G, et al (2020) Geomorphology of Cinque Terre National Park (Italy). Journal of Maps 0:1-14. https://doi.org/10.1080/17445647.2020.1837270

Reichenbach P, Rossi M, Malamud BD, et al (2018) A review of statistically-based landslide susceptibility models. Earth-Science Reviews 180:60-91. https://doi.org/10.1016/j.earscirev.2018.03.001

Roberts DR, Bahn V, Ciuti S, et al (2017) Cross-validation strategies for data with temporal, spatial, hierarchical, or phylogenetic structure. Ecography 40:913-929. https://doi.org/10.1111/ecog.02881

Rojas C, Pino J, Jaque E (2013) Strategic Environmental Assessment in Latin America: A methodological proposal for urban planning in the Metropolitan Area of Concepción (Chile). Land Use Policy 30:519-527. https://doi.org/10.1016/j.landusepol.2012.04.018

Segoni S, Pappafico G, Luti T, Catani F (2020) Landslide susceptibility assessment in complex geological settings: sensitivity to geological information and insights on its parameterization. Landslides 17:2443-2453. https://doi.org/10.1007/s10346-019-01340-2

Sepúlveda SA, Petley DN (2015) Regional trends and controlling factors of fatal landslides in Latin America and the Caribbean. Natural Hazards and Earth System Sciences 15:1821-1833. https://doi.org/10.5194/nhess-15-1821-2015

Steinmann M (1997) The Cuenca basin of southern Ecuador: tectono-sedimentary history and the Tertiary Andean evolution. ETH Zurich

Sturges HA (1926) The Choice of a Class Interval. Journal of the American Statistical Association 21:65-66

Sultana N, Tan S (2021) Landslide mitigation strategies in southeast Bangladesh: Lessons learned from the institutional responses. International Journal of Disaster Risk Reduction 62:102402. https://doi.org/10.1016/j.ijdrr.2021.102402

Swets JA (1988) Measuring the accuracy of diagnostic systems. Science 240:1285-1293. https://doi.org/10.1126/science.3287615

van Westen CJ, Castellanos E, Kuriakose SL (2008) Spatial data for landslide susceptibility, hazard, and vulnerability assessment: An overview. Engineering Geology 102:112-131. https://doi.org/10.1016/j.enggeo.2008.03.010 
van Westen CJ, Rengers N, Soeters R (2003) Use of Geomorphological Information in Indirect Landslide Susceptibility Assessment. Natural Hazards 30:399-419. https://doi.org/10.1023/B:NHAZ.0000007097.42735.9e

Varnes DJ (1984) Landslide hazard zonation: a review of principles and practice. Natural Hazards

Wang HB, Wu SR, Shi JS, Li B (2013) Qualitative hazard and risk assessment of landslides: a practical framework for a case study in China. Nat Hazards 69:1281-1294. https://doi.org/10.1007/s11069-011-0008-1

Warren DL, Seifert SN (2011) Ecological niche modeling in Maxent: the importance of model complexity and the performance of model selection criteria. Ecological Applications 21:335-342. https://doi.org/10.1890/10-1171.1

Wenger SJ, Olden JD (2012) Assessing transferability of ecological models: an underappreciated aspect of statistical validation. Methods in Ecology and Evolution 3:260-267. https://doi.org/10.1111/j.2041-210X.2011.00170.x

Wieczorek GF, Mandrone G, DeCola L (1997) The Influence of Hillslope Shape on Debris-Flow Initiation. ASCE, pp 21-31

Xu C, Xu X, Dai F, et al (2013) Application of an incomplete landslide inventory, logistic regression model and its validation for landslide susceptibility mapping related to the May 12, 2008 Wenchuan earthquake of China. Nat Hazards 68:883-900. https://doi.org/10.1007/s11069-013-0661-7

Zhang T, Mao Z, Wang T (2020) GIS-based evaluation of landslide susceptibility using a novel hybrid computational intelligence model on different mapping units. J Mt Sci 17:2929_ 2941. https://doi.org/10.1007/s11629-020-6393-8

Zhao D, Jiao Y, Wang J, et al (2020) Comparative performance assessment of landslide susceptibility models with presence-only, presence-absence, and pseudo-absence data. J Mt Sci 17:2961-2981. https://doi.org/10.1007/s11629-020-6277-y

Zorn M (2018) Natural Disasters and Less Developed Countries. In: Pelc S, Koderman M (eds) Nature, Tourism and Ethnicity as Drivers of (De)Marginalization: Insights to Marginality from Perspective of Sustainability and Development. Springer International Publishing, Cham, pp 59-78 
